\title{
Study Pressure Fields Affecting Cyclone Rainfall: Case Study of Iran
}

\author{
Iran Salehvand1*, Majid Montazeri², Amir Gandomkar³, Mahdi Moemeni' ${ }^{3}$, \\ Hoshmand Ataei ${ }^{4}$ \\ ${ }^{1}$ Najafabad Branch, Islamic Azad University, Isfahan, Iran \\ ${ }^{2}$ Uiniversity of Isfahan, Isfahan, Iran \\ ${ }^{3}$ Department of Geography, Najafabad Branch, Islamic Azad University, Isfahan, Iran \\ ${ }^{4}$ Department of Geography, Payam Noor Uiniversity of Tehran, Esfhan, Iran \\ Email: ${ }^{*}$ hsabzvare@gmail.com
}

Received 30 September 2014; accepted 21 April 2015; published 29 April 2015

Copyright (C) 2015 by authors and Scientific Research Publishing Inc.

This work is licensed under the Creative Commons Attribution International License (CC BY). http://creativecommons.org/licenses/by/4.0/

(c) (i) Open Access

\section{Abstract}

The aim of this study is the synoptic analysis of the atmospheric conditions concurrent with the heavy precipitations of Lorestan, Fars and Hormozgan provinces and determination of the temporal and spatial distribution of them. Requested atmospheric data for this research was taken from databases related to the National Organization of Atmosphere and Oceanology of United States. More maps of the site were taken. Then the earth surface, 500,700 and 850 Hecto Pascal maps, orbital and meridional winds, earth temperature of earth surface and top of the atmosphere were prepared in Grads software and some of maps were drawn in GIS software. The following results were obtained: On the earth surface map, the main controller role is with the Siberian high-pressure, the Azores's dynamic high-pressure and integrated mode of the Sudan and the Mediterranean low-pressure systems. The main controller role in high levels is with the high altitude center of Azores in the back of the system, the high altitude center of Arabia in the front of the system and deep traffic of North Africa. Another important factor is the moisture mixture of Mediterranean Sea, Red Sea, Persian Gulf, Oman Sea and Indian Ocean. Air rise factor with enhancing meridional winds that causes subsidence of cold air, rising warm air and strengthening the polar front is one of the heavy rainfall conditions too. Eastern winds cause entering of moisture from the Indian Ocean and western winds cause strengthening of cyclones and heavy rainfall in the region.

\section{Keywords}

Isobaric Levels, Heavy Rainfall, Southern Provinces, Synoptic Analysis

\footnotetext{
${ }^{*}$ Corresponding author.
}

How to cite this paper: Salehvand, I., Montazeri, M., Gandomkar, A., Moemeni, M. and Ataei, H. (2015) Study Pressure Fields Affecting Cyclone Rainfall: Case Study of Iran. Atmospheric and Climate Sciences, 5, 129-136. 


\section{Introduction}

The aim of synoptic studies is the determination of interactions between atmosphere and environment [1]. Precipitation systems have a main role in providing water resources; hence the recognition of their properties such as formation, humidity resources and activity location of them is of utmost importance [2]. Heavy rain-falls in anomalistic times are one of important causes of great damages at different geographical locations [3]. Tropical cyclones have a direct relation with the tropical circulation [4]. The main cause of flood is heavy rainfalls. Nowadays one of the proposed tools and techniques in conjunction with heavy rainfall phenomena is the synoptic analysis of these rainfalls because the precise recognition of mechanism and action of atmospheric circulation model and effective parameters on heavy rainfalls are of utmost important [5]. Humidity and rise factor existence is necessary for clouds and rainfall formation at every location [6]. In viewpoint of temporal distribution, Bandali patterns form concurrently with the high intensities mainly at recent of winter season and first of spring season. However, the Bandali patterns with mediocre intensity mainly form at winter season [7]. Fluctuation of precipitation regime in Iran and climate conditions such as short and stormy rainfalls have left devastating floods every year [8]. Humidity factor is more important than rise factor in formation of heavy rainfalls [9]. In the case of synoptic evaluation of rainfall, much research has been done in the country and abroad that a number of them are considered. [10] shows that the main cause of summer heavy rainfall in America is meso-scale factors. He cites the researches of this context. Alijani [11] has studied the synoptic effective factors on formation of Iran rainfalls based on synoptic maps of earth surface and top levels of atmosphere and has proposed the western turbulence factor as the main cause of rainfalls excepting summer reason. He also in other research has evaluated the mechanisms of air rising leads to Iran summer rainfalls and has proposed the earth's warming as the most effective factor of these rainfalls especially in the southeastern region.

\section{Material and Methods/Experimental Details/Methodology}

\subsection{The Study Area}

The information of most daily rainfall of synoptic stations of Fars, Lorestan, Bushehr and Hormozgan provinces were checked and rainfalls with over than $30 \mathrm{~mm}$ depth considered as the heavy rainfall. Figure 1 shows the location of stations and their rainfall amounts.

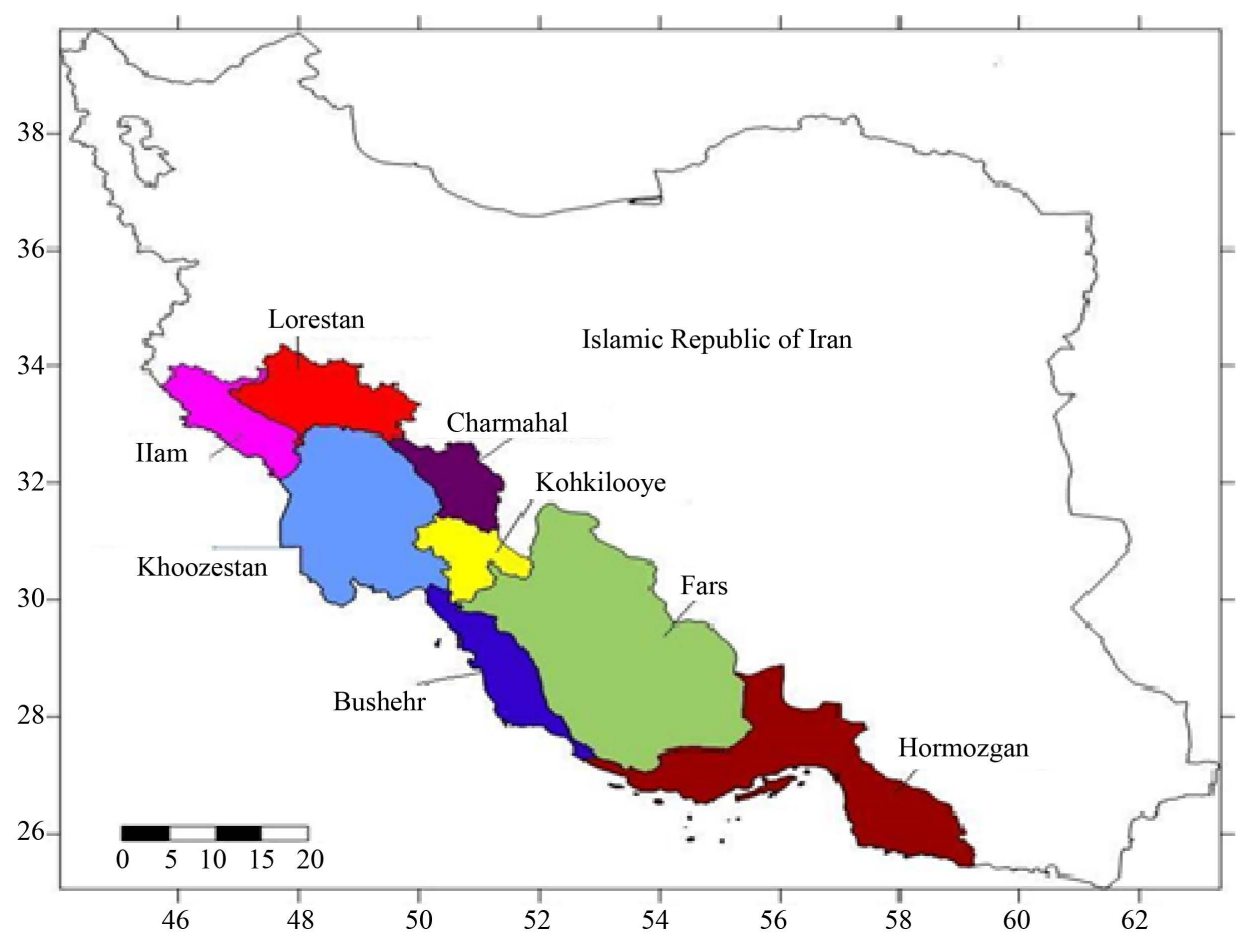

Figure 1. The study area, source authors. 
The information of most daily rainfall of synoptic stations of Fars, Lorestan, Bushehr and Hormozgan provinces were checked and rainfalls with over than $30 \mathrm{~mm}$ depth considered as the heavy rainfall. Figure 1 shows the location of stations.

\subsection{Material and Methods}

In this study rainfall with depths greater than $30 \mathrm{~mm}$ considered as the criterion of days with heavy rainfall that their information was collected of synoptic and climatology stations of studied provinces. Initially databases of surface environment were provided that includes information of daily rainfall of south and southwest of Iran. Another database was provided for the atmospheric data that determines the atmospheric flows and includes pressure levels and earth surface data. Requested atmospheric data for this research was taken from databases related to the National Organization of Atmosphere and Oceanology of United States.

www.esrl.noaa.gov/psd/data/gridded/data.ncep.reanalysis.pressure.html. More maps of the site were taken. These databases encompass the period from 1948 to now and cover four observations at synoptic hours (zero, six, twelve and eighteen) for every day. Moreover daily and monthly mean of atmospheric data was provided in this database. The greatest daily precipitation was used in this study. Research method in this study is circulating environmental approach. Main reason of choosing this approach as a systematic method to study is that the spatial and temporal variation of rainfall is more intense than in other climatic variables. Then the earth's surface, 500,700 and 850 Hecto Pascal maps, orbital and meridional winds, earth temperature of earth surface and top of the atmosphere were prepared in Grads software and some of maps were drawn in GIS software.

\subsection{Results of Research}

\section{Synoptic Analysis of Surface Pressure (SLP) 1998}

1) Figure 2: Slp 31 December 1998: polar high-pressure with central core was seen in north of the map. And in its below island's low-pressures have formed tri-cores, one on the Russia, others on Scandinavian and Europe
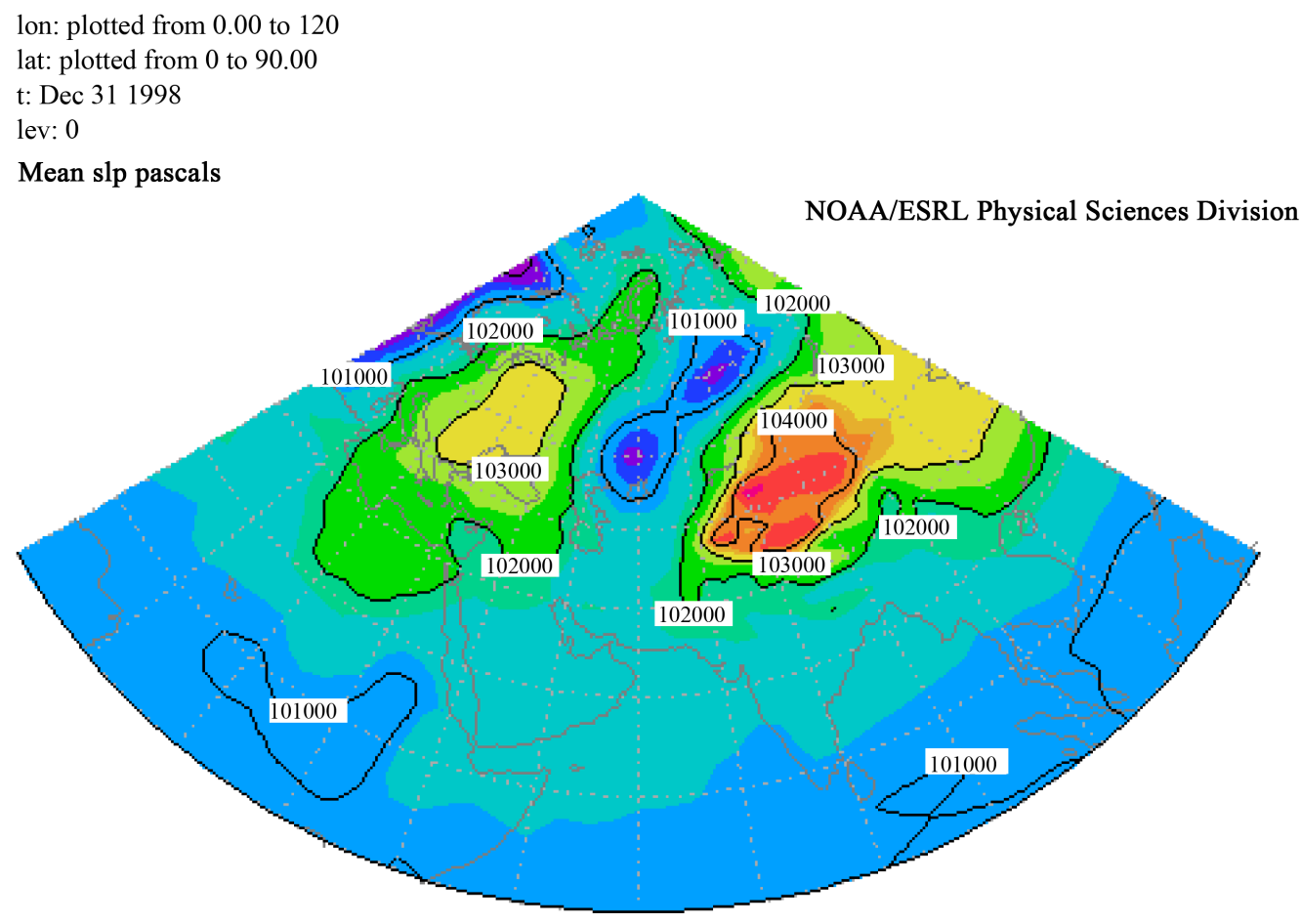

NOAA/ESRL Physical Sciences Division 
north. Siberia's high-pressure was placed below these low-pressures with multiple cores. Sudanese low-pressure has placed below the Siberia's high-pressure forming two cores of pressure. One high-pressure also is forming in north of Africa.

2) Figure 3: Slp 1 January 1998: Siberia high-pressure has moved to east. Its tabs became weaker than the previous day, and the width of high-pressure has declined. Par line of 1020 which interconnected two highpressures of polar and Siberia in the previous day, today surround two low-pressures of island and south polar. The low-pressure core on the Russia has formed two cores. Par line of 1020 where located below the Persian Gulf today has moved upward the Iran. Tropical side high-pressure come forward and combined with Siberia's high-pressure. Sudanese low-pressure has formed two cores and moved upwards relative to its past location.

3) Figure 4: Slp 2 January 1998: polar high-pressure also changed its location and moved towards the east and 1040 curve became smaller than yesterday. Convergence of Sudanese low-pressure in the south and divergence of two high-pressures in both sides caused the formation of a low-pressure on the Iran. This low-pressure is migrant Silicon that if it has been located on a region it acts as an aerologic bomb and has heavy rainfalls.

\subsection{Synoptic Analysis of Geopotential Heath (HGT) 1998}

Figure 5: Hgt 31 December 1998: it has formed in the top low height atmosphere because of air rise from lowpressures. But near the pole two high height cores were formed because of air descend on polar high-pressure. A ridge has formed on the Siberia which lead to air descend and region coldness because this cold weather direct to the surrounding by high-pressure. In the conjunction of two mentioned high-pressures in the north of Caspian, Mediterranean, and Black Seas a Traff has been formed. Half of a ridge which has seen in the west of map is on the tropical side high-pressure and it causes air descends towards Mediterranean and Egypt. The Traff formed in the north of Africa and Arabia could be an introduction of a heavy rain fall in the west of Iran because it carries high moisture. Iran country is located under descend of cold weather of Siberia.

Figure 6: Hgt 1 January 1998: A Traff has formed in 500 levels on the Sudanese low-pressure. The air on the tropical side high-pressure catches the Mediterranean moist and Europe coldness and has downward movement

lon: plotted from 0.00 to 120

lat: plotted from 0 to 90.00

t: Jan 11998

lev: 0

Mean slp pascals

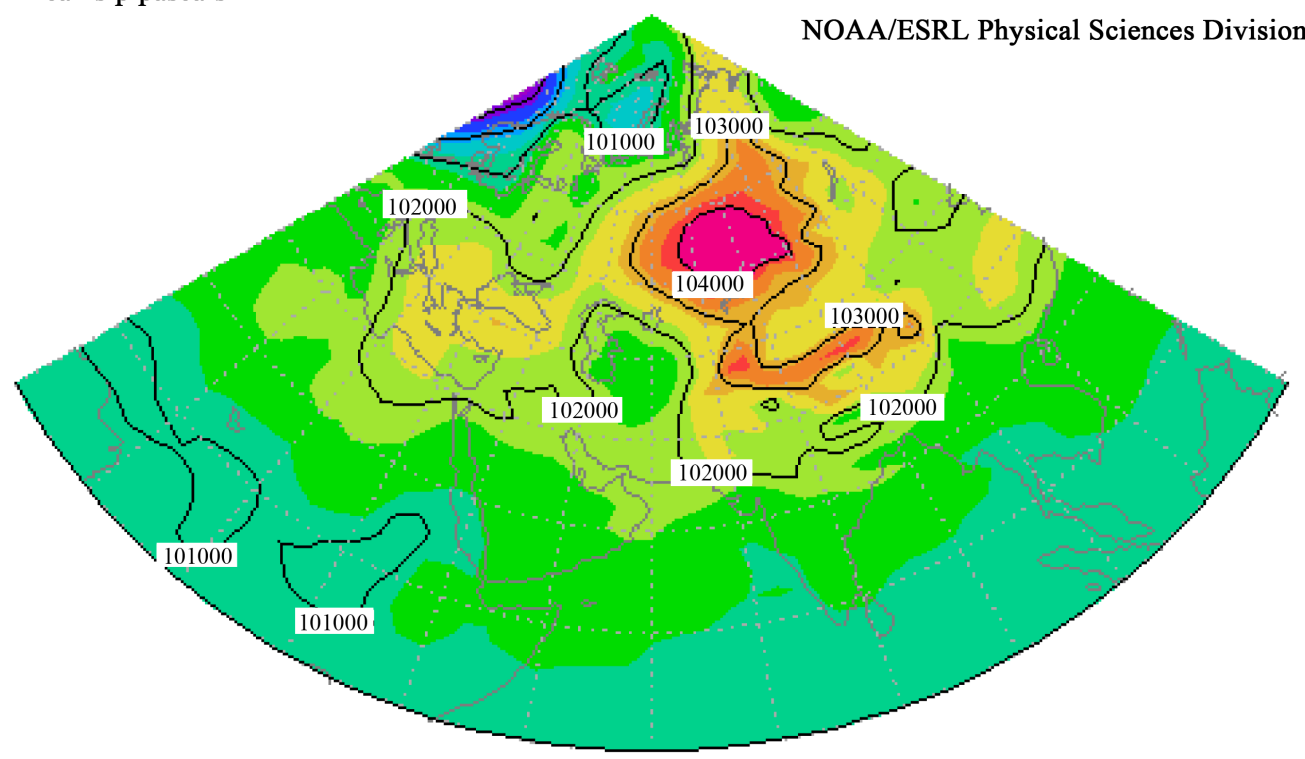


lon: plotted from 0.00 to 120

lat: plotted from 0 to 90.00

t: Jan 21998

lev: 0

Mean slp pascals
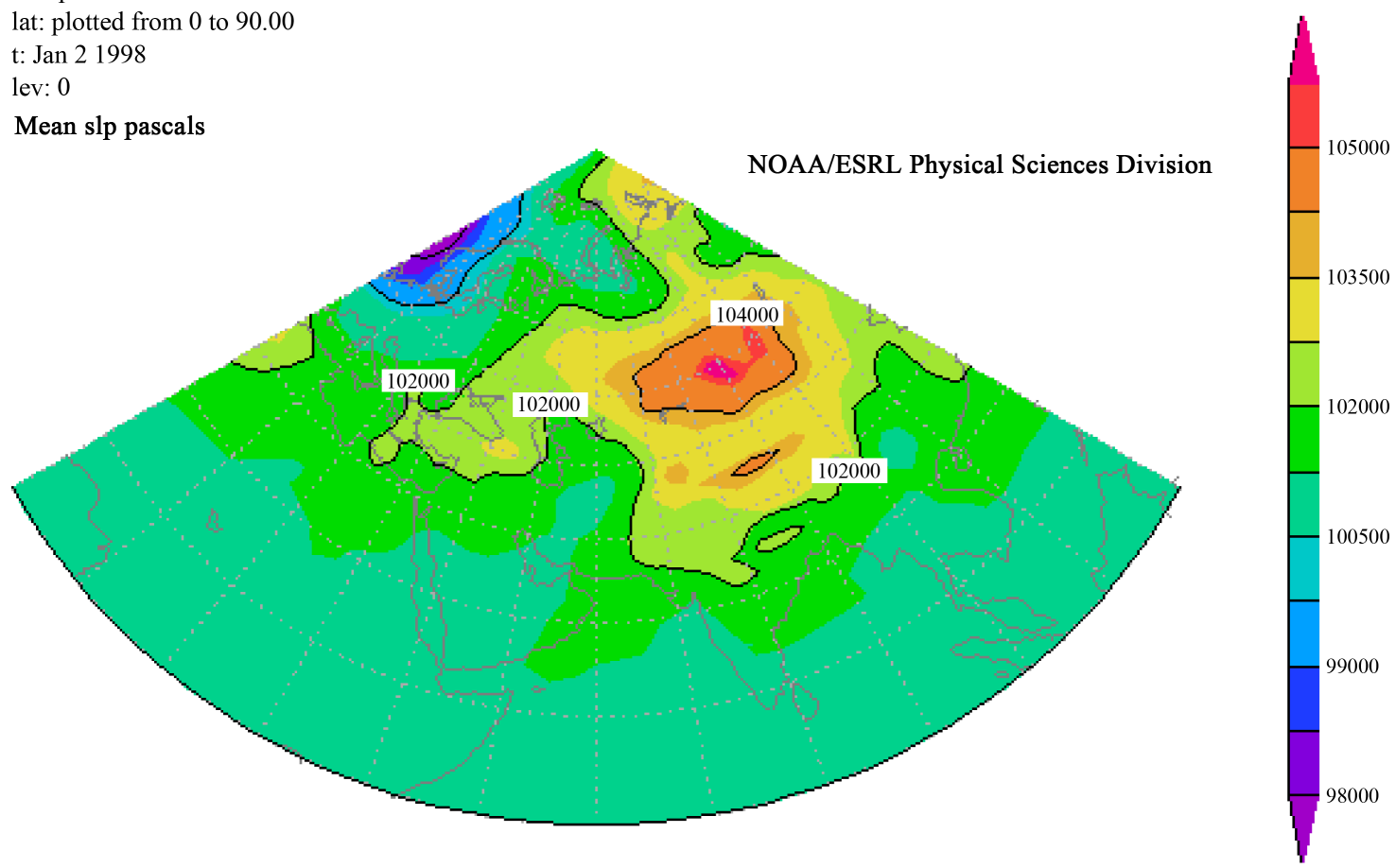

MAX $=105952$

NCEP Reanalysis Daily Averages Surface Level GrADS image

$\mathrm{MIN}=97335$

Figure 4. Surface pressure map on 2 January.

lon: plotted from 0.00 to 120

lat: plotted from 0 to 90.00

lev: a50.00

t: Dec 311998

Mean hgt. $\mathrm{m}$

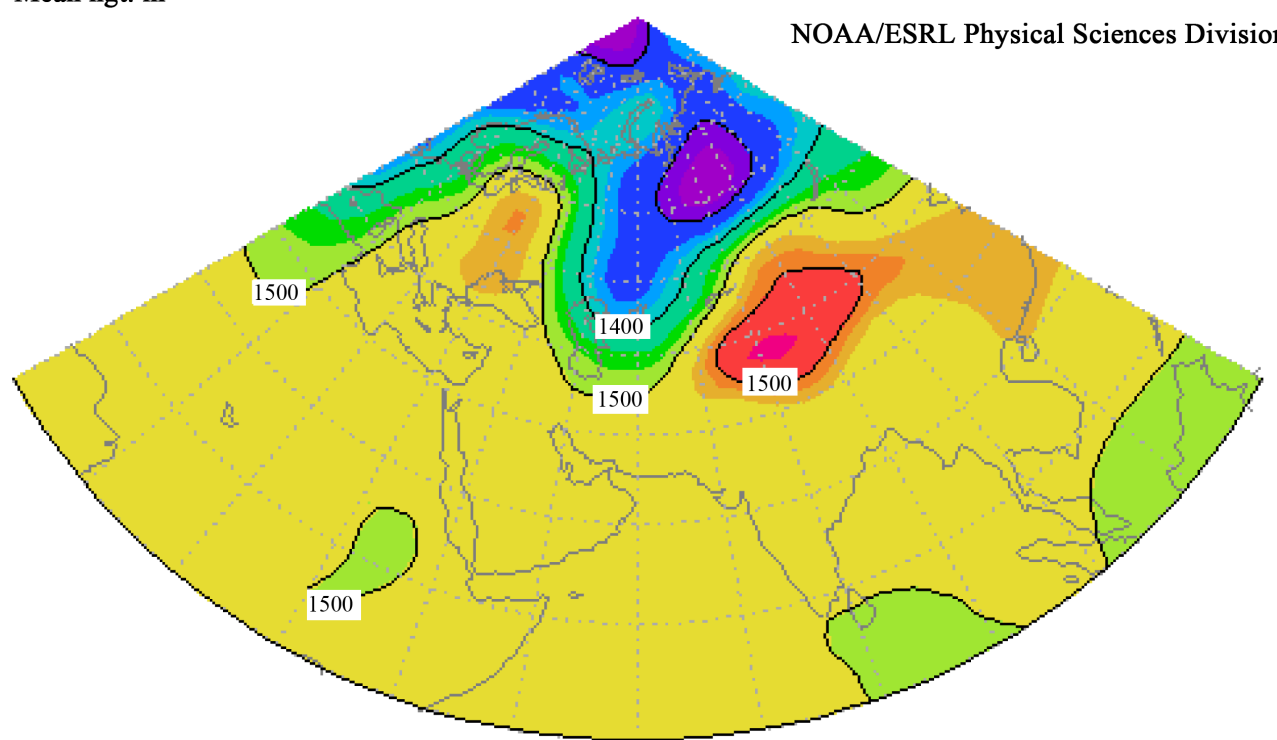



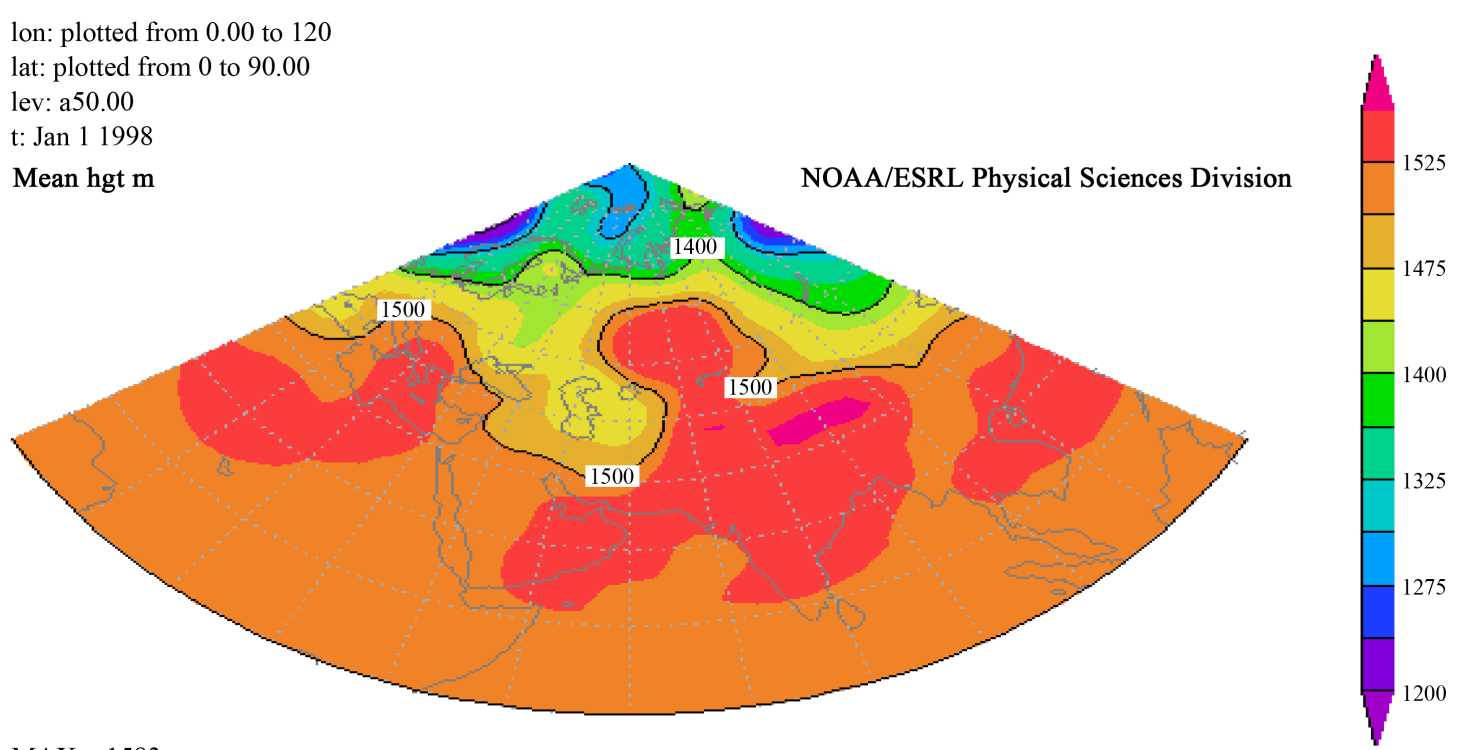

MAX $=1583$

$\mathrm{MIN}=1185$

NCEP Reanalysis Daily Averages Surface Level GrADS image

Figure 6. Geopotential Heath (HGT) map on 1 January.

to Red Sea. Arabia peninsula is in front of Traff air rise and if possible it could rain. South of Iran has also heavy rainfall.

Figure 7: Hgt 2 January1998: previous day Traff has moved closer. On top of the silicon there is air rise and because this silicon has caught the moist from surrounded seas it caused many rains especially in south of Iran.

1) Slp 4 January 2014 A: in the earth maps: Siberia thermal high-pressure has formed in the north of Caspian Sea. Island's low-pressure has located on the Europe. There is another low-pressure in the east of map that it may be polar side low-pressure. Sudanese low-pressure and India Ocean low-pressure have located in the south of Siberia's high-pressure.

2) Hgt 4 January 2014 A1: in the above atmosphere: a high-height has formed upwards the Siberia' highpressure and air movement is as subsidence. On the top of the Sudanese low-pressure a low-height or a hole has formed which its movement is ascending. In the location of 20 degree north a high-height has formed which its high-pressure location is invisible in the earth and it's the same Bermuda high-pressure.

3) Slp 5 January 2014 B: polar side low-pressure core has moved to the east. Island and Sudanese low-pressures are also moving because of convergence and anti-clockwise rotation from the below on Siberia highpressure. Air descends in Siberia high-pressure and air divergence caused coldness distribution and strength the core of this high-pressure.

4) Hgt 5 January 2014 B1: from properties of today in the 500 atmosphere: intensification of above convergence in the east of Siberia high-pressure, weakness of polar side Traff, advancement and deepening of the hod which has formed in the Iraq, advancement of the ridge which was in the west of map, and formation of another Traff in 20 degree north on the Africa.

5) Slp 6 January 2014 C: Siberia high-pressure has appeared stronger and wider than previous day. Tropical side high-pressure which was not seen in the previous days has advanced. Par line of 1050 of Sudanese lowpressure has changed its location and moved closer, and its close curve has become bigger.

6) Hgt 6 January $2014 \mathrm{C} 1$ : in the above convergence region of two mentioned high-pressures there located a cold hole. This cold hole which is full of cold air carries the Mediterranean moist and by ascending the air in its east the moist moved to the east. But a ridge which has located on the tropical side high-pressure is between two Traffs on the Mediterranean and west of Iran. And this factor moved the cold air to Iran southwest and caused heavy snowfall in the provinces of Fars and Kohgiloye and Boyer Ahmad. Iran has located in front of this Traff and this cause heavy rainfall.

\section{Discussion and Conclusion}

In these two days, there are differences from reasons of rainfall view. In 1998 from north to south the following 
lon: plotted from 0.00 to 120

lat: plotted from 0 to 90.00

lev: a50.00

t: Jan 21998

Mean hgt m

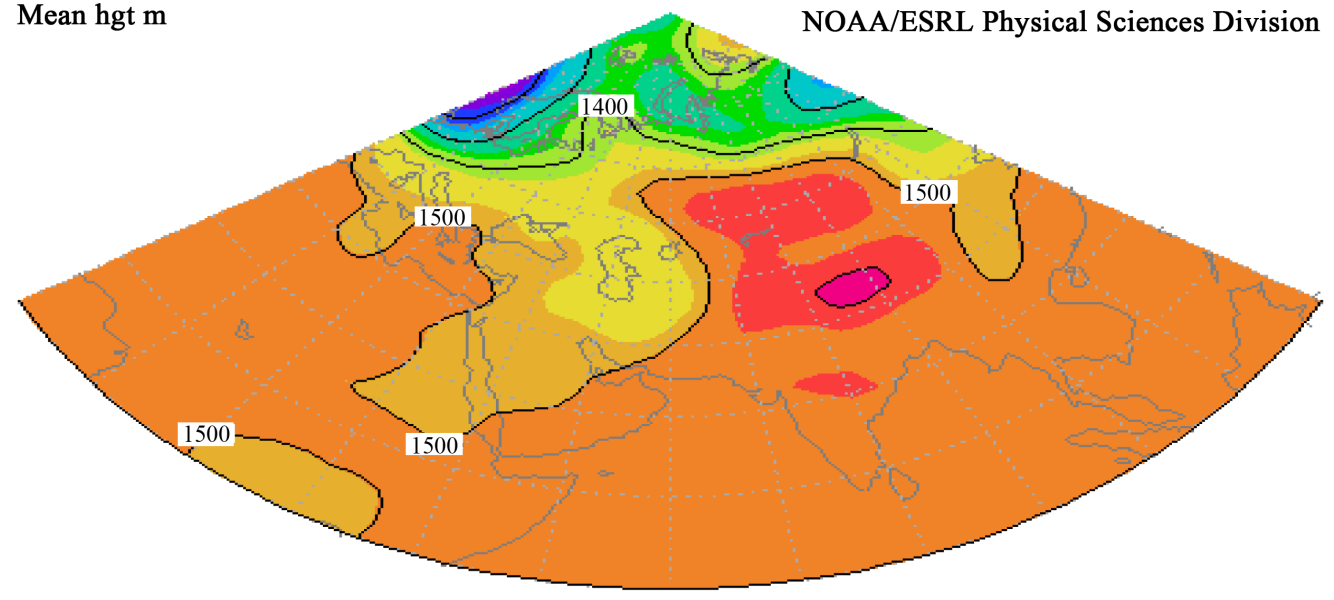

NOAA/ESRL Physical Sciences Division

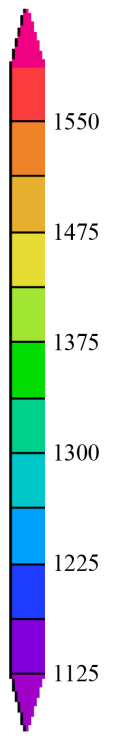

$\mathrm{MAX}=1617$

$\mathrm{MIN}=1104$

NCEP Reanalysis Daily Averages Surface Level GrADS image

Figure 7. Geopotential Heath (HGT) map on 2 January.

cores are seen in the maps of two past days: polar high-pressure in the pole region, three cores of polar side lowpressure (island low-pressure), three cores of high-pressure (Siberia and Bermuda), and two cores of low-pressure (tropical convergence). While two days before heavy fall of 2014, the only high-pressure in the region was Siberia and in its north and south located two low-pressure cores. Heavy rainfall in 1998 was rain and in 2014 it appeared as heavy snowfall on the heights. In 1998 low-pressure or migrant silicon was the reason of heavy fall but in 2014 cold hole in Mediterranean has caused heavy fall. In 1998 wave pattern has caused the heavy fall and in 2014 A bi-arrived thermal descent caused heavy fall in the region. Iranian Plateau due to its specific location is at the transition point than large-scale general circulation models of the troposphere and is seating location of the extra tropical, subtropical and tropical systems (Azizi, 1385). Rain is a climatic variable that has high temporal and spatial variety. Its spatial distribution is affected by earth altitude, slope and etc. (Joule, 2003). Thus Iran rainfalls arise from different systems. Rain is the most important environmental phenomenon that is done with the special circumstances such as air rise, moisture content and Wind River formation. Special conditions need heavy rainfall too. In this study, creating blocking conditions in the north of the country is one the important factors of heavy rainfall in the south. Another important factor is the moisture mixture of Mediterranean Sea, Red Sea, Persian Gulf, Oman Sea and Indian Ocean. Air rise factor with enhancing Meridional winds that causes subsidence of cold air, rising warm air and strengthening the polar front is one of the heavy rainfall conditions too. Eastern winds cause entering of moisture from the Indian Ocean and western winds cause strengthening of cyclones and heavy rainfall in the region.

\section{References}

[1] Sadeghi, S., Hossins, B.S.R., Friend, R. and Blacksmith, B.-Z. (2012) Synoptic Analysis of Cold Wave in the North East of Iran. Geography and Environmental Hazards, 3, 107-123.

[2] Ghaffarian, P., Mshkvaty, A.H., Freedom, M. and Farm Farahani, M. (2010) The Synoptic Precipitation in the North West of Iran, a Case Study Extreme Precipitation Stations in Urmia. Journal of Climatology, 2, 13-24.

[3] Mousavi, B. and Ashraf, M.B. (2010) Investigated the Vertical Profile of Rainfall Has Led to Severe Summer Weather (Case Study: Mashhad). Soil and Water Journal, 24, 10-48.

[4] Lashkari, H. (2008) Synoptic Analysis of the Causes Precipitation Sylza in Golestan Province. Journal of Human Journal, 12, 181-211.

[5] Parandeh, K. (2011) Evaluation of Heavy Rainfall in Southern Iran Synoptic Case Study Due December 1, 1984 to 4 January 1985. Journal of Geography, Planning and Environmental Dalaki River Watershed, 41, 123-136. 
[6] Noori, H.M.A. (2012) Of Clouds and Heavy Rains Causing Heavy Southern Shores of the Caspian. Geography and Environmental Planning, 47, 1-22.

[7] Azizi, Q.A. (2006) Synoptic Analysis of the Spatial Distribution of Extreme Precipitation and North Khorasan Province. Journal of Geographical Perspective, 95, 65-112.

[8] Lashkari, H. and Kay, G. (1389) Synoptic Analysis Gvnv Storm and Its Effects on South-East of Iran. Journal of Geography and Environmental Planning, 21, 1-20.

[9] Alijani, B. and Mahmoud, R. (2010) Synoptic Analysis of Heavy Rainfall in South East Sixth of January 2008. Journal of Climatology, 5, 1-12.

[10] Hand, W. (2003) A Historical Study of Exterm Rainfall Events in the 20th Century. Numerical Weather Prediction.

[11] Alijani, B. (1998) Mechanisms of Rainfall Required, the Faculty of Letters and Human Sciences. Teacher Development, 85, 53-45. 